Subscriber access provided by King Abdullah University of Science and Technology Library

Communication

\title{
Is NiCo2S4 really a semiconductor?
}

Chuan Xia, Peng Li, Appala Naidu Gandi, Udo Schwingenschlögl, and Husam N. Alshareef

Chem. Mater., Just Accepted Manuscript • DOI: 10.1021/acs.chemmater.5b01843 • Publication Date (Web): 31 Aug 2015

Downloaded from http://pubs.acs.org on September 6, 2015

\section{Just Accepted}

"Just Accepted" manuscripts have been peer-reviewed and accepted for publication. They are posted online prior to technical editing, formatting for publication and author proofing. The American Chemical Society provides "Just Accepted" as a free service to the research community to expedite the dissemination of scientific material as soon as possible after acceptance. "Just Accepted" manuscripts appear in full in PDF format accompanied by an HTML abstract. "Just Accepted" manuscripts have been fully peer reviewed, but should not be considered the official version of record. They are accessible to all readers and citable by the Digital Object Identifier (DO|®). "Just Accepted" is an optional service offered to authors. Therefore, the "Just Accepted" Web site may not include all articles that will be published in the journal. After a manuscript is technically edited and formatted, it will be removed from the "Just Accepted" Web site and published as an ASAP article. Note that technical editing may introduce minor changes to the manuscript text and/or graphics which could affect content, and all legal disclaimers and ethical guidelines that apply to the journal pertain. ACS cannot be held responsible for errors or consequences arising from the use of information contained in these "Just Accepted" manuscripts. 


\title{
Is $\mathrm{NiCO}_{2} \mathrm{~S}_{4}$ really a semiconductor?
}

\author{
Chuan Xia ${ }^{\star}$, Peng Li*, Appala Naidu Gandi, Udo Schwingenschlögl, Husam N. Alshareef* \\ Materials Science and Engineering, King Abdullah University of Science and Technology (KAUST), Thuwal 23955, \\ Kingdom of Saudi Arabia
}

\begin{abstract}
NiCo}_{2} \mathrm{~S}_{4}$ is a technologically important electrode material that has recently achieved remarkable performance in pseudocapacitor, catalysis, and dye-synthesized solar cell applications. ${ }^{1-5}$ Essentially, all reports on this material have presumed it to be semiconducting, like many of the chalcogenides, with a reported band-gap in the range of 1.2-1.7 $\mathrm{eV}^{6,7}$ In this report, we have conducted detailed experimental and theoretical studies, most of which done for the first time, which overwhelmingly show that $\mathrm{NiCo}_{2} \mathrm{~S}_{4}$ is in fact a metal. We have also calculated the Raman spectrum of this material and experimentally verified it for the first time, hence clarifying inconsistent Raman spectra reports. Some of the key results that support our conclusions include: (1) the measured carrier density in $\mathrm{NiCo}_{2} \mathrm{~S}_{4}$ is $3.18 \times 10^{22} \mathrm{~cm}^{-3},(2) \mathrm{NiCo}_{2} \mathrm{~S}_{4}$ has a room temperature resistivity of around $10^{3} \mu \Omega \mathrm{cm}$ which increases with temperature, (3) $\mathrm{NiCo}_{2} \mathrm{~S}_{4}$ exhibits a quadratic dependence of the magnetoresistance on magnetic field, (4) thermopower measurements show an extremely low Seebeck coefficient of $5 \mu \mathrm{V} \mathrm{K}$, , (5) first principles calculations confirm that $\mathrm{NiCo}_{2} \mathrm{~S}_{4}$ is a metal. These results suggest that it is time to re-think the presumed semiconducting nature of this promising material. They also suggest that the metallic conductivity is another reason (besides the known significant redox activity) behind the excellent performance reported for this material.
\end{abstract}

$\mathrm{NiCo}_{2} \mathrm{~S}_{4}$ has a normal thiospinel crystal structure ${ }^{8}$ and was first described in 1850 upon discovery in the Stahlberg Mine in Müsen, Siegerland, North Rhine Westphalia, Germany, and was named for that locality. Previous report shows that siegenite could deliver a high conductivity of $1.25 \times 10^{6} \mathrm{~s} \mathrm{~m}^{-1}$ at room temperature. ${ }^{9}$ The siegenite $\left(\mathrm{NiCO}_{2} \mathrm{~S}_{4}\right)$ system has recently become a heavily studied electrode material for energy applications, including dye-sensitized solar cells (DSSCs), supercapacitors, and fuel cells with excellent results. For instance, Banerjee et al. reported that $\mathrm{NiCO}_{2} \mathrm{~S}_{4}$ based DSSCs show a high catalytic activity towards the $\mathrm{I}^{-} / \mathrm{I}^{3-}$ redox couple, and lead to an impressive efficiency of $6.9 \%$, compared with $7.7 \%$ obtained with a Pt electrode in similarly constructed devices. ${ }^{10}$ This replacement of $\mathrm{Pt}$ by $\mathrm{NiCO}_{2} \mathrm{~S}_{4}$ enables a lowcost DSSC device since the Pt catalyst accounts for nearly $50 \%$ of the cost. ${ }^{3}$ Further, it has been demonstrated by many groups that nanostructured $\mathrm{NiCO}_{2} \mathrm{~S}_{4}$ can be used in fuel cells and supercapacitors with very good energy conversation and storage performance. ${ }^{3,7,11-13}$ These good device performances across many applications have commonly been attributed to the high conductivity of $\mathrm{Ni}$ $\mathrm{Co}_{2} \mathrm{~S}_{4}$, which has recently been attributed to its narrow band gap, implying that $\mathrm{NiCo}_{2} \mathrm{~S}_{4}$ is a typical semiconductor. While the thiospinel siegenite has been widely studied for energy harvesting and storage applications, its fundamental properties have actually remained poorly studied. Even its Raman spectrum remains unknown.

Here we show that the sporadic reports on its physical properties have not firmly established the correct properties of this material. For example, Chen et al. re- ported that siegenite is a semiconductor with a direct band gap of $1.2 \mathrm{eV}$ using UV-Vis measurements. ${ }^{6}$ Du et al. concluded that siegenite was semiconducting with a direct transition of $1.71 \mathrm{eV} .^{7}$ Furthermore, Yang et al. showed that the $\mathrm{F}_{2 \mathrm{~g}}$ and $\mathrm{A}_{1 \mathrm{~g}}$ Raman modes of $\mathrm{NiCo}_{2} \mathrm{~S}_{4}$ are located at 523.5 and $671.2 \mathrm{~cm}^{-1}$, respectively. ${ }^{14}$ Unfortunately, as demonstrated later in the manuscript, all the abovementioned reports on the basic properties of $\mathrm{NiCo}_{2} \mathrm{~S}_{4}$ are inaccurate. Hence, we felt that more detailed studies are needed to understand the origin of the remarkably good performance of this material in various applications.
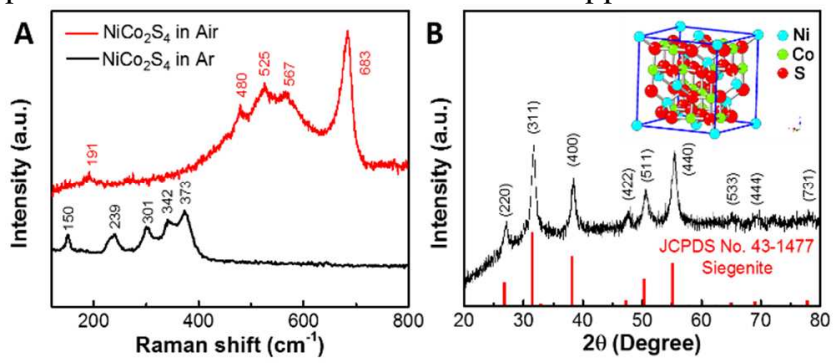

Figure 1. (A) Typical XRD pattern of as-prepared $\mathrm{NiCo}_{2} \mathrm{~S}_{4}$ at room temperature, with the crystal model as inset. (B) Raman spectrum measured in air and argon atmosphere.

As a typical normal spinel, the crystal structure of $(\mathrm{Ni})_{\mathrm{A}}\left[\mathrm{Co}_{2}\right]_{\mathrm{B}} \mathrm{S}_{4}$ was verified by neutron diffraction by Nakagawa et al. ${ }^{8}$ Nickel and Cobalt are found to occupy tetrahedral sites (A) and octahedral sites (B), respectively. In a unit cell, only one eighth of the A sites are occupied by $\mathrm{Ni}^{2+}$ and half of the $\mathrm{B}$ sites are occupied by $\mathrm{Co}^{3+}$. The inset 
of Figure 1a represents the crystal structure of $\mathrm{NiCo}_{2} \mathrm{~S}_{4}$ with space group $F \bar{d} 3 \mathrm{~m}$. The XRD patterns of assynthesized $\mathrm{NiCo}_{2} \mathrm{~S}_{4}$ are shown in Figure 1a. All diffraction peaks can be recognized as the standard $\mathrm{NiCo}_{2} \mathrm{~S}_{4}$ thiospinel structure with no detectable secondary phases. The lattice constant of $\mathrm{NiCo}_{2} \mathrm{~S}_{4}$ was calculated to be $9.319 \AA$ according to the strongest diffraction peak (311), consistent with previous investigations. ${ }^{3}$ Notably, the full width at half maximum (FWHM) of the peaks for the asobtained thiospinel was broad, clearly illustrating that the samples were nanocrystalline in nature. The average grain size of the nanocrystal was estimated to be $10.32 \mathrm{~nm}$ based on the FWHM (o.8 ${ }^{\circ}$ ) of the strongest peak (311) and the empirical Scherrer formula $d=0.9 \lambda /(\beta \cos \theta)$, in which $\beta$ and $\theta$ are the FWHM (in radian) and Bragg angle, respectively. Although the diffraction intensity of all peaks was somewhat low, the relative intensity among the diffraction peaks was consistent with the standard nickel cobalt thiospinel structure, indicative of the successful and controlled synthesis of $\mathrm{NiCO}_{2} \mathrm{~S}_{4}$ by the hydrothermal method.

Table 1: Experimental and calculated Raman Vibration mode of $\mathrm{NiCo}_{2} \mathrm{~S}_{4}$

\begin{tabular}{llllll}
\hline \hline & $\mathbf{A}_{\mathrm{lg}}$ & $\mathbf{E}_{\mathrm{g}}$ & $\mathbf{T}_{\mathbf{2 g}, \mathbf{1}}$ & $\mathbf{T}_{\mathbf{2 g}, \mathbf{2}}$ & $\mathbf{T}_{\mathbf{2 g}, 3}$ \\
\hline Experiment & 373 & 239 & 342 & 301 & 150 \\
Calculation & 401 & 253 & 364 & 322 & 163 \\
Difference & $-6.9 \%$ & $-5.5 \%$ & $-6.0 \%$ & $-6.5 \%$ & $-7.9 \%$ \\
Atoms involved & $\mathrm{S}$ & $\mathrm{S}$ & $\mathrm{S}, \mathrm{Ni}$ & $\mathrm{S}, \mathrm{Ni}$ & $\mathrm{S}, \mathrm{Ni}$ \\
\hline \hline
\end{tabular}

The lattice dynamics of $\mathrm{NiCo}_{2} \mathrm{~S}_{4}$ has never been wellstudied except for one literature report showing Raman active $\mathrm{T}_{2 \mathrm{~g}}\left(523.5 \mathrm{~cm}^{-1}\right)$ and $\mathrm{A}_{1 \mathrm{~g}}\left(671.2 \mathrm{~cm}^{-1}\right)$ modes under atmosphere. ${ }^{14}$ However, those vibration modes are much closer to the features of typical spinel oxides $\left(\mathrm{NiCo}_{2} \mathrm{O}_{4}\right){ }^{15}$ In addition, there is apparently no calculation of the Raman modes of $\mathrm{NiCO}_{2} \mathrm{~S}_{4}$. Given that the sulfides are easily oxidized by laser heating during measurement, ${ }^{16}$ Raman scattering experiments should be performed carefully to exclude the unintentional oxidation of the $\mathrm{NiCo}_{2} \mathrm{~S}_{4}$ phase. Therefore, we employed Argon atmosphere to measure the Raman features of $\mathrm{NiCo}_{2} \mathrm{~S}_{4}$. The results are shown in Fig. 1b. For comparison, the Raman spectra measured in air are also shown in Figure $1 \mathrm{~b}$. Actually, all observed modes for the sample measured in air can be indexed as Raman features of $\mathrm{NiCo}_{2} \mathrm{O}_{4} \cdot{ }^{17}$ A third Raman measurement was done, where the data was collected in air while inserting a filter between the sample and laser (Figure $\mathrm{S} 1$ ). The data in Figure $\mathrm{S}_{1}$ show a superposition of two sets of Raman vibration modes from $\mathrm{NiCo}_{2} \mathrm{~S}_{4}$ and $\mathrm{NiCo}_{2} \mathrm{O}_{4}$, clearly indicating that laser induced oxidation takes place. A similar phenomenon was also observed in the $\mathrm{Fe}_{3} \mathrm{~S}_{4}$ system. ${ }^{16}$ In order to check the validity of the experimental Raman results for $\mathrm{NiCo}_{2} \mathrm{~S}_{4}$, a theoretical analysis based on the normal thiospinel $\mathrm{NiCo}_{2} \mathrm{~S}_{4}$ was performed. This analysis predicts five Raman active modes: $E_{g}, A_{1 g}$ and three $T_{2 g}$. The calculated and experimental frequencies of the Ra- man active modes are summarized in Table 1 . The stretching of $\mathrm{S}$ atoms towards the tetrahedral site $\mathrm{Ni}$ atom and the bending of the $\mathrm{S}-\mathrm{Ni}_{\text {tetra }}-\mathrm{S}$ bonds causes the $\mathrm{A}_{1 \mathrm{~g}}(373 \mathrm{~cm}$ $\left.{ }^{1}\right)$ and $E_{g}\left(239 \mathrm{~cm}^{-1}\right)$ mode, respectively. The three $T_{2 g}$ modes $\left(150,301\right.$, and $\left.342 \mathrm{~cm}^{-1}\right)$ can be ascribed to asymmetric bending of S-Ni $\mathrm{N}_{\text {tetra }}-\mathrm{S}$ bonds. All the calculated frequencies agree well with the experimental values with less than $10 \%$ difference.

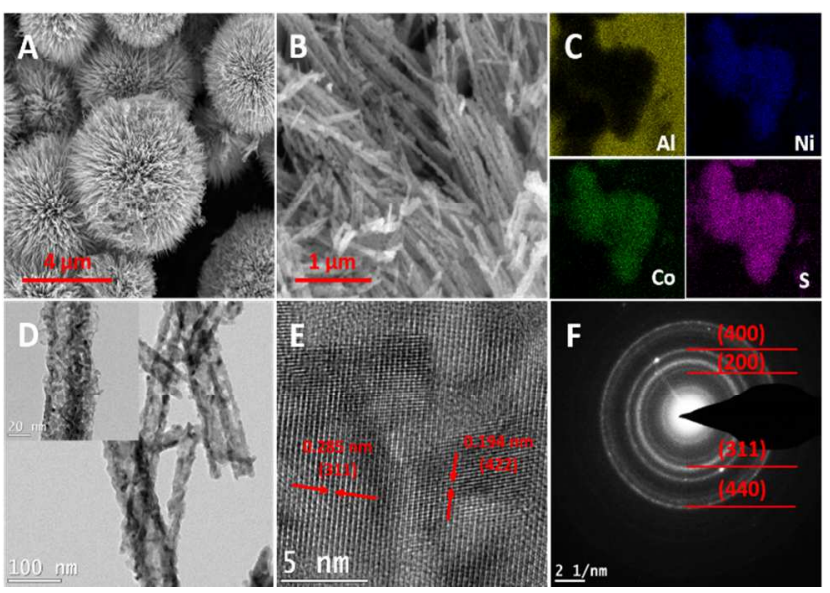

Figure 2. (A-C) Representative FESEM images of as-prepared $\mathrm{NiCo}_{4} \mathrm{~S}_{4}$ with corresponding EDX element mapping of aluminum, nickel, cobalt and sulfur. (D-F) Typical TEM and HRTEM images of the nanostructured samples with corresponding SAED pattern.

Figure 2a-b show that the hydrothermally obtained powders of $\mathrm{NiCo}_{2} \mathrm{~S}_{4}$ maintain a uniform urchin-like morphology with nanocrystalline self-assembled nanotube emanating radially grown from the center. These hollow nanotubes likely result from the well-kown Kirkendall effect of the sacrificial precursor template during the anion ion exchange process. ${ }^{18}$ Energy dispersive spectra (EDS) were collected to provide further insight into the elemental composition and distribution of the asprepared $\mathrm{NiCo}_{2} \mathrm{~S}_{4}$. An even distribution of the elements $\mathrm{Ni}, \mathrm{Co}$, and $\mathrm{S}$ (Figure $2 \mathrm{c}$ ) on the surface is clearly visible, further demonstrating the successful preparation of high quality thiospinel $\mathrm{NiCO}_{2} \mathrm{~S}_{4}$. The corresponding signal of $\mathrm{Al}$ is from the sample holder. Figure $2 \mathrm{~d}-\mathrm{f}$ shows the TEM images of the $\mathrm{NiCo}_{2} \mathrm{~S}_{4}$ nanotube and corresponding selected area electron diffraction (SAED). The representative TEM image shows the $\mathrm{NiCo}_{2} \mathrm{~S}_{4}$ nanotubes with a diameter of about $50 \mathrm{~nm}$, with the individual nanotube itself composed of numerous nanocrystallites of around 10 $\mathrm{nm}$ size, consistent with the results from the SEM and XRD analyses. The high resolution TEM image reveals that the lattice plane distances are 0.285 and $0.194 \mathrm{~nm}$, which fits well to the (311) and (422) interplanar spaces in siegenite. The lattice fringes with different orientations suggest that the as-obtained $\mathrm{NiCo}_{2} \mathrm{~S}_{4}$ is polycrystalline in nature, which is confirmed by its corresponding SAED. The supercapacitor performance of as-prepared $\mathrm{NiCO}_{2} \mathrm{~S}_{4}$ nanopowder was checked and is shown in Figure S2. 
It has been reported that thiospinel $\mathrm{NiCo}_{2} \mathrm{~S}_{4}$ has a much higher conductivity than its oxide counterpart (Ni$\mathrm{CO}_{2} \mathrm{O}_{4}$ ) and that it is a semiconductor with a direct band gap of $1.2 \mathrm{eV}$ based on UV-Vis measurements. ${ }^{6}$ Yet, the reported UV-Vis spectra ${ }^{6,19}$ showed a nearly straight line, unlike the UV-Vis spectra of typical semiconductors, ${ }^{20}$ implying that no absorption has actually occurred during the measurement. We observe a similar behavior in our material and find it hard to make any definite conclusion from UV-Vis measurements (Figure $\mathrm{S}_{3}$ ). Therefore, we have studied the transport behavior using pellets prepared by pressing $\mathrm{NiCo}_{2} \mathrm{~S}_{4}$ powder, as shown in Figure za. We were surprised to observe that $\mathrm{NiCo}_{2} \mathrm{~S}_{4}$ actually conducts like a typical metal with a positive temperature coefficient of resistance. Notably, the resistivity of $\mathrm{NiCo}_{2} \mathrm{~S}_{4}$ increased linearly in the temperature range of 40 to $300 \mathrm{~K}$. The linear relationship between resistivity and temperature $\left(\rho_{x x} \propto T\right)$ confirms its metallic behavior and shows that electron-phonon scattering dominates in $\mathrm{NiCo}_{2} \mathrm{~S}_{4}$. The room temperature resistivity of our $\mathrm{NiCo}_{2} \mathrm{~S}_{4}$ sample is approximately $10^{3} \mu \Omega \mathrm{cm}$, indicating excellent conductivity. The Seebeck coefficient of pressed $\mathrm{NiCo}_{2} \mathrm{~S}_{4}$ pellets was measured as a function of temperature and the results are shown in Figure $\mathrm{S}_{4}$. An extremely low value of around 5 $\mu \mathrm{V} \mathrm{K} \mathrm{K}^{-1}$ was obtained, which strongly supports the metallic nature of thiospinel $\mathrm{NiCO}_{2} \mathrm{~S}_{4}$. Further, an illustration of the good conductivity, in comparison to other known semiconducting materials, is shown in Figure $\mathrm{S}_{5}$. It can be seen that the conductivity of as-prepared $\mathrm{NiCo}_{2} \mathrm{~S}_{4}$ is much higher than the typical semiconductors such as $\mathrm{Co}_{3} \mathrm{O}_{4}$ and $\mathrm{NiCO}_{2} \mathrm{O}_{4}$.
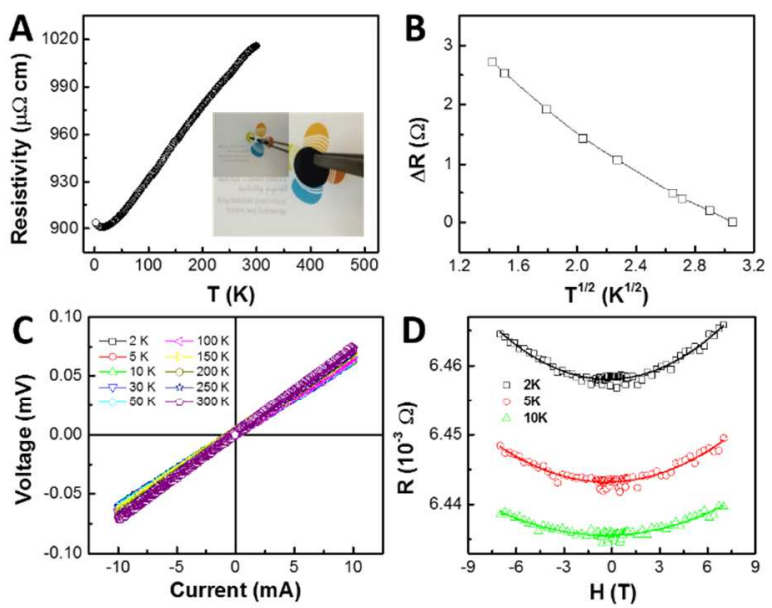

Figure 3. (A) Resistivity of $\mathrm{NiCo}_{2} \mathrm{~S}_{4}$ as a function of temperature. (B) $\Delta R$ versus $T^{1 / 2}$ at low temperature and (C) Voltagecurrent (I-V) curves and (D) magnetoresistance against magnetic field for various temperatures. Note that the inset of (A) shows a photo of the pressed $\mathrm{NiCO}_{2} \mathrm{~S}_{4}$ pellet.

Attributed to the severe interfacial scattering among the nanoparticles, the residual resistivity at $2 \mathrm{~K}$ is rather large with $\rho_{2 \mathrm{~K}} / \rho_{3 \mathrm{ooK}} \approx 0.9$, meaning that much higher conductivity can be expected in $\mathrm{NiCo}_{2} \mathrm{~S}_{4}$ single crystals or epitaxial thin films. Interestingly, the resistivity increases slightly for $T<20 \mathrm{~K}$ with decreasing temperature, which can be ascribed to the quantum three-dimensional weak localization effect. According to this effect, a linear dependence of $\Delta R$ on $\sqrt{T}$ is expected and observed (Figure $3 \mathrm{~b})$. It is believed that the weak localization is caused by the electron scattering from defects and interfaces between the crystal grains. ${ }^{21}$ In order to check the data accuracy, voltage-current (IV) curves were measured in a fourterminal setup at different temperatures, as shown in Figure 3c. Obviously, all the acquired IV curves are linear in the range of $-10 \mathrm{~mA}$ to $10 \mathrm{~mA}$ indicating an Ohmic behavior. Figure 3d displays the magnetoresistance of $\mathrm{NiCo}_{2} \mathrm{~S}_{4}$ as a function of the magnetic field at low temperatures. A pronounced positive and quadratic behavior is observed, which is one of the characteristics of normal metals. The magnetoresistance measurement verified the metallic nature of $\mathrm{NiCO}_{2} \mathrm{~S}_{4}$. A slight discrepancy of the magnetoresistance at $\mathrm{H}= \pm 7 \mathrm{~T}$ originates from a weak interference of the Hall signal due to minor geometric misalignment. Breakdown of the weak localization at low temperature is usually expected under magnetic field, indicative of a small negative magnetoresistance $(\sim-0.1 \%)$ at low fields. Yet, this phenomenon is not observed in our case, probably because we approach the sensitivity limit of the equipment.
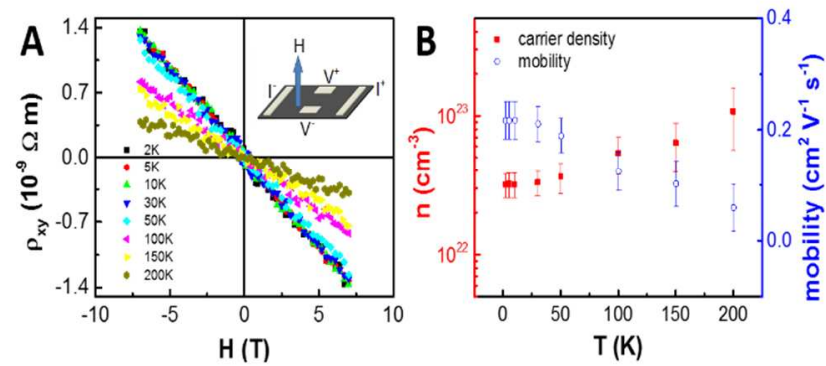

Figure 4. (A) Magnetic field dependent Hall resistivity of $\mathrm{NiCo}_{2} \mathrm{~S}_{4}$ at different temperatures. The inset gives the Hall measurement configuration. (B) Calculated carrier density (red) and mobility (blue) as a function of temperature.

The Hall resistivity of the pressed $\mathrm{NiCo}_{2} \mathrm{~S}_{4}$ pellet is presented in Figure $4 \mathrm{a}$, in which all the curves are corrected by removing the longitudinal resistance contribution. The measurement configuration is given in Figure $4 \mathrm{a}$ as an inset. The linear dependence of the Hall resistivity as a function of the magnetic field in the whole temperature range, with a negative slope, indicates that the electrical transport in $\mathrm{NiCO}_{2} \mathrm{~S}_{4}$ is dominated by electrons instead of holes. The carrier density can be obtained using the slope of the curves $\left(R_{x y}=R_{0} H\right.$, Hall coefficient $R_{0}=$ cient $\left.R_{0}=1 / n e\right)$ in Figure 4a. Moreover, the electron mobility is calculated through $\mu=R_{0} / \rho_{x x}$. Figure $4 \mathrm{~b}$ presents the carrier density and electron mobility as a function of temperature. The carrier density and mobility of the Ni$\mathrm{Co}_{2} \mathrm{~S}_{4}$ pellet remain nearly constant, with fluctuations on the same order of magnitude as the change in the parameters over the studied temperature range. The carrier density at $2 \mathrm{~K}$ is calculated to be $3.18 \times 10^{22} \mathrm{~cm}^{-3}$, which is as high as that of silver $\left(8.37 \times 10^{22} \mathrm{~cm}^{-3}\right)$. The relatively low mobility is probably related to defect scattering in the nanocrystalline samples. 
Furthermore, first principles calculations were carried out to determine if theory can confirm the experimental results showing the metallic nature of this compound. According to neutron diffraction, the crystal structure of $\mathrm{NiCo}_{2} \mathrm{~S}_{4}$ is a normal spinel. ${ }^{8}$ Starting from the experimental structural parameters, we arrive at a lattice constant of $9.274 \AA$ after structure optimization, which is in good agreement with the measured value of $9.319 \AA$. Our calculations show non-spin polarization. According to the densities of states shown in Figure 5 , there is strong hybridization between the $\mathrm{S} p$ states, and the $\mathrm{Ni}$ and $\mathrm{Co} d$ states near the Fermi level (o eV). Electronic bands are crossing the Fermi level, which is reflected by a finite density of states. Hence, $\mathrm{NiCo}_{2} \mathrm{~S}_{4}$ is undoubtedly metallic, and the theoretical calculation is in accord with our experimental results.

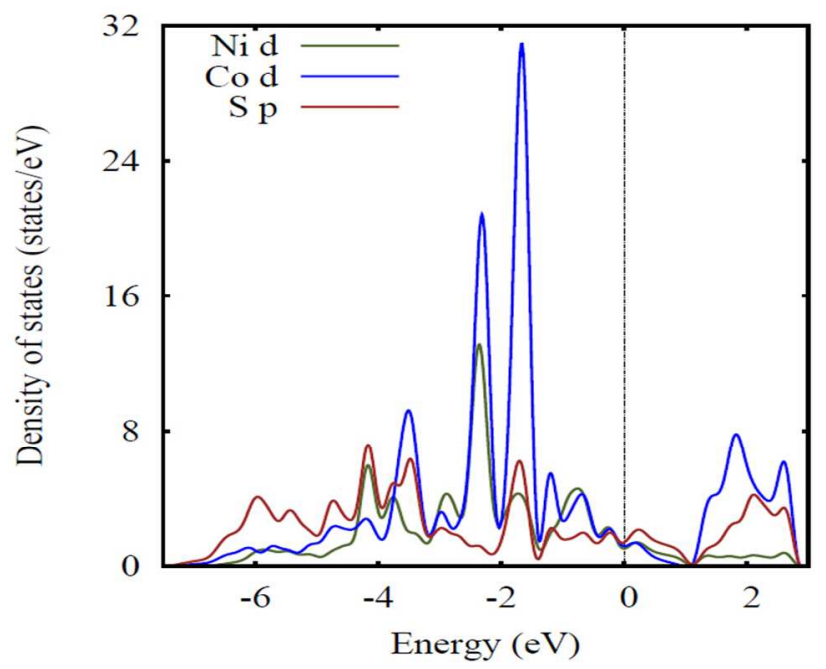

Figure 5. Site projected density of states of $\mathrm{NiCO}_{2} \mathrm{~S}_{4}$.

In summary, single phase powders and pellets of thiospinel $\mathrm{NiCo}_{2} \mathrm{~S}_{4}$ were successfully synthesized by the hydrothermal method. Several experimental and theoretical analyses reveal that $\mathrm{NiCo}_{2} \mathrm{~S}_{4}$ is in fact a metal rather than a semiconductor, in contrast to has been recently reported. This conclusion explains the excellent electrochemical performance reported for this compound in a wide spectrum of applications (supercapacitors, fuel cells, and solar cells). We believe that in addition to good electrochemical activity of the cations ( $\mathrm{Ni}$ and $\mathrm{Co}$ ), the metallic conductivity of $\mathrm{NiCo}_{2} \mathrm{~S}_{4}$ is a key factor in the excellent performance it has achieved in various applications.

\section{ASSOCIATED CONTENT}

Supporting Information. Experimental details, Raman measurement, supercapacitor perfotmance, Seebeck coefficient and the illustration of conductivity of $\mathrm{NiCo}_{2} \mathrm{~S}_{4}$ are included. This material is available free of charge via the Internet at http://pubs.acs.org."

\section{AUTHOR INFORMATION}

\section{Corresponding Author}

*E-mail: husam.alshareef@kaust.edu.sa

\section{Author Contributions}

$\ddagger$ Chuan Xia and $\ddagger$ Peng Li contributed equally. All authors have given approval to the final version of the manuscript.

\section{ACKNOWLEDGMENT}

Research reported in this publication has been supported by King Abdullah University of Science and Technology (KAUST).

\section{REFERENCES}

(1) Zhu, Y. R.; Wu, Z. B.; Jing, M. J.; Yang, X. M.; Song, W. X.; Ji, X. B., Mesoporous $\mathrm{NiCo}_{2} \mathrm{~S}_{4}$ nanoparticles as high-performance electrode materials for supercapacitors. Journal of Power Sources 2015, 273, 584-59o. (2) Shen, L. F.; Wang, J.; Xu, G. Y.; Li, H. S.; Dou, H.; Zhang, X. G., $\mathrm{NiCo2}_{4}$ Nanosheets Grown on Nitrogen-Doped Carbon Foams as an Advanced Electrode for Supercapacitors. Advanced Energy Materials 2015, 5, 1400977.

(3) Zhang, Z. Y.; Wang, X. G.; Cui, G. L.; Zhang, A. H.; Zhou, X. H.; Xu, H. $\mathrm{X}$;; Gu, L., NiCo2S4 sub-micron spheres: an efficient non-precious metal bifunctional electrocatalyst. Nanoscale 2014, 6, 3540-3544.

(4) Yang, J.; Bao, C. X.; Zhu, K.; Yu, T.; Li, F. M.; Liu, J. G.; Li, Z. S.; Zou, Z. G., High catalytic activity and stability of nickel sulfide and cobalt sulfide hierarchical nanospheres on the counter electrodes for dye-sensitized solar cells. Chemical Communications 2014, 50, 4824-4826.

(5) Shi, Z. W.; Lu, H.; Liu, Q.; Cao, F. R.; Guo, J.; Deng, K. M.; Li, L. A., Efficient p-type dye-sensitized solar cells with all-nano-electrodes: $\mathrm{NiC}_{2} \mathrm{~S}_{4}$ mesoporous nanosheet counter electrodes directly converted from $\mathrm{NiCO}_{2} \mathrm{O}_{4}$ photocathodes. Nanoscale Research Letters 2o14, 9, 608. (6) Chen, H. C.; Jiang, J. J.; Zhang, L.; Wan, H. Z.; Qi, T.; Xia, D. D. Highly conductive $\mathrm{NiCo}_{2} \mathrm{~S}_{4}$ urchin-like nanostructures for high-rate pseudocapacitors. Nanoscale 2013, 5, 8879-8883.

(7) Du, W. M.; Zhu, Z. Q.; Wang, Y. B.; Liu, J. N.; Yang, W. J.; Qian, X. F.; Pang, H., One-step synthesis of $\mathrm{CoNi}_{2} \mathrm{~S}_{4}$ nanoparticles for supercapacitor electrodes. Rsc Advances 2014, 4, 6998-7002.

(8) Knop, O.; Reid, K. I. G.; Sutarno; Nakagawa, Y., Chalkogenides of Transition Elements .6. X-Ray Neutron and Magnetic Investigation of Spinels $\mathrm{Co}_{3} \mathrm{O}_{4} \mathrm{NiCo}_{2} \mathrm{O}_{4} \mathrm{Co}_{3} \mathrm{~S}_{4}$ and $\mathrm{NiCo}_{2} \mathrm{~S}_{4}$. Canadian Journal of Chemistry 1968, 46, 3463-3476.

(9) Bouchard, R. J.; Russo, P. A.; Wold, A., Preparation and Electrical Properties of Some Thiospinels. Inorganic Chemistry 1965, 4, 685-688.

(10) Banerjee, A.; Upadhyay, K. K.; Bhatnagar, S.; Tathavadekar, M.; Bansode, U.; Agarkar, S.; Ogale, S. B., Nickel cobalt sulfide nanoneedle array as an effective alternative to $\mathrm{Pt}$ as a counter electrode in dye sensitized solar cells. Rsc Advances 2014, 4, 8289-8294.

(11) Xiao, J. W.; Wan, L.; Yang, S. H.; Xiao, F.; Wang, S., Design Hierarchical Electrodes with Highly Conductive $\mathrm{NiCo}_{2} \mathrm{~S}_{4}$ Nanotube Arrays Grown on Carbon Fiber Paper for High-Performance Pseudocapacitors. Nano Letters 2014, 14, 831-838.

(12) Chen, W.; Xia, C.; Alshareef, H. N., One-Step Electrodeposited Nickel Cobalt Sulfide Nanosheet Arrays for High-Performance Asymmetric Supercapacitors. Acs Nano 2014, 8, 9531-9541.

(13) Li, P.; Jiang, E.; Bai, H., Fabrication of ultrathin epitaxial $\gamma-\mathrm{Fe}_{2} \mathrm{O}_{3}$ films by reactive sputtering. Journal of Physics D: Applied Physics 2011, 44, 075003.

(14) Yang, J.; Ma, M. Z.; Sun, C. C.; Zhang, Y. F.; Huang, W.; Dong, X. C., Hybrid NiCo2S4@MnO2 heterostructures for high-performance supercapacitor electrodes. Journal of Materials Chemistry A 2015, 3, 12581264.

(15) Li, W.; Xin, L.; Xu, X.; Liu, Q.; Zhang, M.; Ding, S.; Zhao, M.; Lou, X., Facile synthesis of three-dimensional structured carbon fiber-NiCo2 $\mathrm{O}_{4}$ $\mathrm{Ni}(\mathrm{OH})_{2}$ high-performance electrode for pseudocapacitors. Scientific reports 2015, 5, 9277.

(16) Li, G. W.; Zhang, B. M.; Yu, F.; Novakova, A. A.; Krivenkov, M. S.; Kiseleva, T. Y.; Chang, L.; Rao, J. C.; Polyakov, A. O.; Blake, G. R.; de Groot, R. A.; Palstra, T. T. M., High-Purity $\mathrm{Fe}_{3} \mathrm{~S}_{4}$ Greigite Microcrystals for Magnetic and Electrochemical Performance. Chemistry of Materials 2014, 26, 5821-5829.

(17) Windisch, C. F.; Exarhos, G. J.; Sharma, S. K., Influence of temperature and electronic disorder on the Raman spectra of nickel cobalt oxides. Journal of Applied Physics 2002, 92, 5572-5574. 
(18) Zhang, Y. F.; Ma, M. Z.; Yang, J.; Sun, C. C.; Su, H. Q.; Huang, W.; Dong, X. C., Shape-controlled synthesis of $\mathrm{NiCo}_{4} \mathrm{~S}_{4}$ and their charge storage characteristics in supercapacitors. Nanoscale 2014, 6, 9824-9830. (19) Du, W.; Zhu, Z.; Wang, Y.; Liu, J.; Yang, W.; Qian, X.; Pang, H., Onestep synthesis of $\mathrm{CoNi}_{2} \mathrm{~S}_{4}$ nanoparticles for supercapacitor electrodes. RSC Advances 2014, 4, 6998-7002.
(20) Hu, L.; Wu, L.; Liao, M.; Hu, X.; Fang, X., Electrical transport properties of large, individual $\mathrm{NiCo}_{2} \mathrm{O}_{4}$ nanoplates. Advanced Functional Materials 2012, 22, 998-1004.

(21) Li, Z.; Lin, J.-J., Electrical resistivities and thermopowers of transparent Sn-doped indium oxide films. Journal of applied physics 2004, 96, 5918-5920.

\section{TOC}

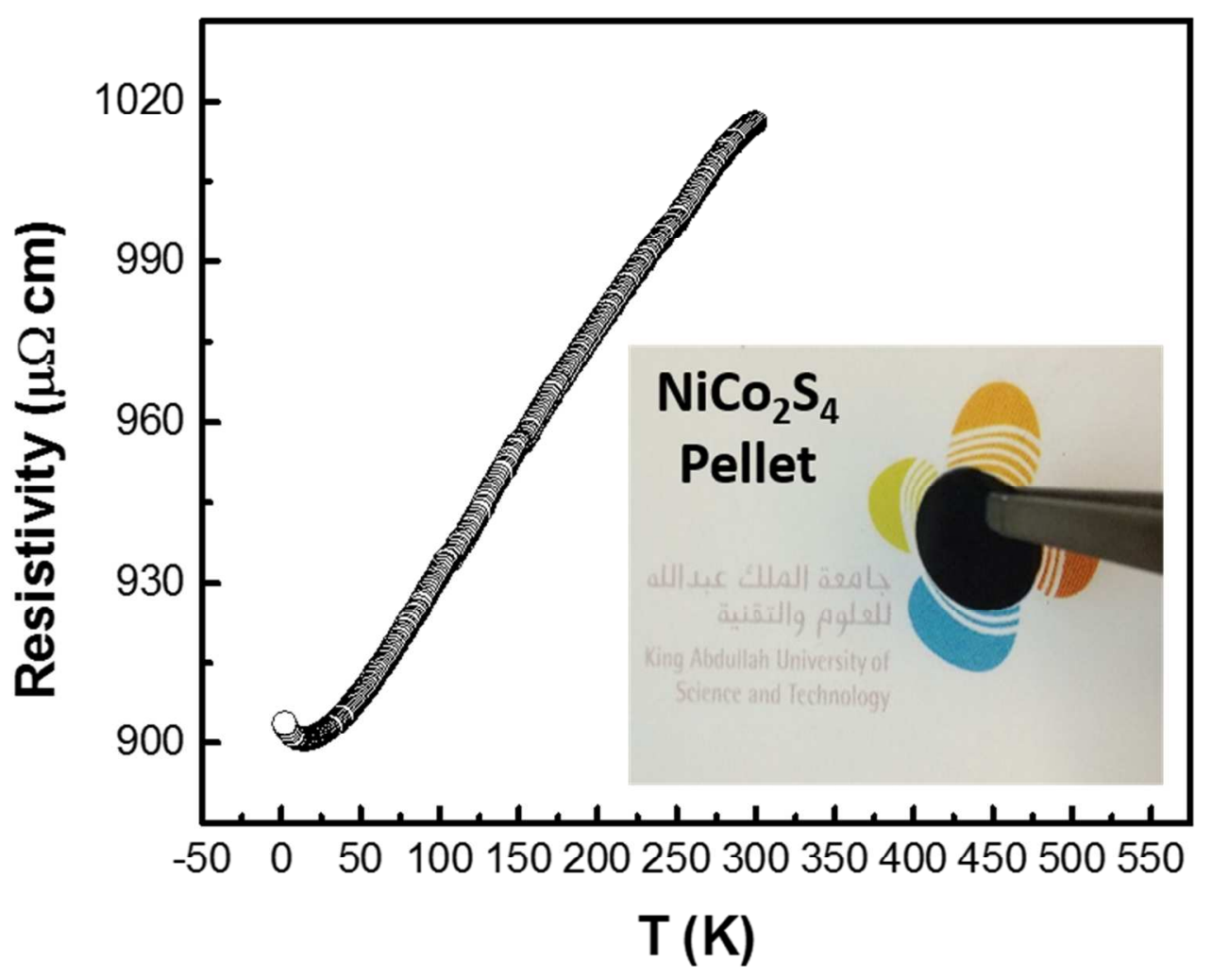

